\title{
Equipo médico para investigación del método psicoprofiláctico de analgesia obstétrica
}

Desde mediados del año pasado se organizó en Bogotá un equipo médico destinado a estudiar, investigar y practicar en nuestro medio el método psicoprofiláctico del parto.

El equipo ha quedado integrado en la siguiente forma: Obstetras: doctores Hernando Amaya León, Belisario Calderón M., Miguel A. Fernández Bastidas, Alberto Gómez Tamayo, Guillermo López Escobar y Carlos R. Silva Mojica. Psiquiatra: doctor Juan B. Castaño Castillo. Pediatra: doctor Guillermo Lesmes Alford. Enfermera: señora Cecilia Silva de Mojica.

Para la práctica del método se han tenido en cuenta todos los detalles que este procedimiento requiere para la obtención de resultados aceptables: minuciosa educación prenatal; adecuada preparación emocional y física para el parto; selección de pacientes; clínica apropiada; colaboración del personal de la clínica, internos, enfermeras y hermanas; entrenamiento de la paciente en la misma clínica, etc.

Las experiencias se han venido realizando con las pacientes particulares de los médicos integrantes del equipo en la Clínica Palermo y los resultados que hasta el presente se han obtenido, muy similares a los anotados en otros países, son muy alentadores.

Dentro del plan del equipo figuran las sesiones cientificas mensuales, las que se han venido efectuando regularmente, destinadas a estudiar y discutir las historias de los casos atendidos y los informes personales que sobre su parto presenta cada paciente; a elaborar la estadística; a criticar los métodos, las conferencias, las prácticas kinesiterápicas, y en fin, a estudiar el perfeccionamiento del control y apoyo médico del trabajo del parto, base fundamental para el éxito del método. Se leen además artículos sobre la materia aparecidos en diverșas revistas extranjeras, se estudian trabajos e informes y se procura en toda forma que los diversos eslabones del equipo educador-enfermera instructo- 
ra-obstetra-pediatra y psiquiatra, marchen perfectamente coordinados.

Otros puntos contemplados en el programa de acción del equipo son los siguientes:

a) Difundir el conocimiento del método dentro del cuerpo médico.

b) Procurar la extensión del método hasta entidades hospita arias. Respecto de este particular ya se ha logrado iniciar la práctica del método, con firme estabilidad, en el Departamento de Maternidad del Hospital San José y también se han hecho algunos ensayos en el Instituto de Protección Materno Infantil Concepción Villaveces de Acosta destinados a la elaboración de una tesis doctoral.

c) Procurar que en el programa de obstetricia de las distintas facultades del país se incluya la enseñanza del método psicoprofiláctico.

Parece que en la Facultad de Medicina de la Universidad Nacional se viene enseñando este método desde hace dos años.

d) Procurar igualmente que en las escuelas de enfermeras se imparta a las alumnas una sólida instrucción sobre este punto ya que el papel de la enfermera es decisivo para el buen resultado del método.

e) Efectuar cursos de post-graduados sobre la materia para médicos de provincia.

f) Presentar en ia próxima Convención Nacional de Obstetricia y Ginecología los primeros resultados del método psicoprofiláctico en Colombia.

g) Mantener intercambio de correspondencia y experiencias con los especialistas extranjeros que en una u otra forma practican métodos psico-físicos de analgesia obstétrica: Lamaze, Read, Toms, Goodrich, Baez, Palacios Acosta, etc.

h) Facilitar a los colegas que lo soliciten toda clase de información al respecto: literatura, programas, organización, plan de clases, métodos kinesiterápicos y sistemas de relajación muscular, etc.

A quien le interese puede dirigirse a la oficina de la Sociedad Colombiana de Obstetricia y Ginecología, Bogotá, Colombia. Avenida Jiménez, número 5-16. Oficina 302. La correspondencia debe enviarse a esta dirección y dirigida a "EQUIPO MEDICO DE ESTUDIOS PSICOPROFILACTICOS DE ANALGESIA OBSTETRICA". 